Tohoku J. exp. Med., 1981, 135, 43-49

\title{
The Corrected Protein Equation to Estimate Plasma Colloid Osmotic Pressure and Its Development on a Nomogram
}

\author{
Sumio Nitta, Takamasa Ohnuki, Kazuhiro Ohkuda, \\ Tasuku Nakada and Norman C. Staub* \\ Department of Surgery, The Research Institute for Chest \\ Diseases and Cancer, Tohoku University, Sendai 980 and \\ * Cardiovascular Research Institute, University of California, \\ San Francisco, USA
}

Nitta, S., Ohnuki, T., Ohkuda, K., Nakada, T. and Staub, N.C. The Corrected Protein Equation to Estimate Plasma Colloid Osmotic Pressure and Its Development on a Nomogram. Tohoku J. exp. Med., 1981, 135 (1), 43-49 — Examining the internal discrepancies of three equations (Landis and Pappenheimer 1965) which represent the relationship between colloid osmotic pressures (COP) and normal human plasma proteins, the authors derived a corrected globulin equation: $\mathrm{COPglb}=1.3 \mathrm{c}+0.14 \mathrm{c}^{2}+0.006 \mathrm{c}^{3}$ (COP: $\mathrm{mmHg}$, c: protein content, $\mathrm{g} / 100$ $\mathrm{ml}$ ), instead of their $\mathrm{COPglb}=1.6 \mathrm{c}+0.15 \mathrm{c}^{2}+0.006 \mathrm{c}^{3}$, when $\mathrm{A} / \mathrm{G}$ (albumin-globulin ratio) $=1.1$. as they had described. Revising the former globulin equation again, based upon the current estimate of $\mathrm{A} / \mathrm{G}=1.8$, we derived a new globulin equation. Our new plasma equation, consisting of their albumin equation and our revised globulin equation, is $\mathrm{COPpl}=\alpha\left(2.8 \mathrm{c}+0.18 \mathrm{c}^{2}+0.012 \mathrm{c}^{3}\right)+\beta\left(0.9 \mathrm{c}+0.12 \mathrm{c}^{2}+0.004 \mathrm{c}^{3}\right)$, where $\alpha$ and $\beta$ stand for albumin and globulin fraction, respectively. The last, being generalized for plasma with any protein compositions, and closely corresponded to the values directly measured in normal human plasma with variable protein compositions, we developed it on a nomogram for practical use. colloid osmotic pressure; plasma protein composition; equation; nomogram

The colloid osmotic pressure (COP) of plasma and lymph plays an essential role in transvascular fluid physiology. Most investigators (Landegard-Pederson 1967; Zweifach and Interglieta 1971) report that only the directly measured COP can be relied upon and that no theoretical understanding can be applied to determine the COP of plasma whithin a wide range of protein composition.

However, the directly measured data must be corrected for the increment in $\mathrm{pH}$ which always occurs during the separation of blood (Landis and Pappenheimer 1965).

This disadvantage in direct measurement calls for the determination of an accurate relationship between the COP of the plasma and its protein composition.

In 1965, Landis and Pappenheimer derived three protein colloid osmotic pressure equations, of which the plasma equation is often referred to as the COP of the normal plasma and has been proved in human, rat and sheep samples (Navar

Received for publication, October 14, 1980. 
and Navar 1977; Demling et al. 1980). As the authors briefly mentioned in a previous paper, their equations include internal inconsistencies and cannot be generalized at all when plasma composition deviates from the normal range (Nitta et al. 1976).

Discussing the discrepancies of these equations, the authors intend to propose a possible plasma equation applicable for samples within a wide range of protein compositions. The correlation of the our corrected equation with the directly measured COP of the normal plasma is discussed.

\section{Materials and Methods}

1) Landis and Pappenheimer described the following two empirically supported equations representing the osmotic pressure-concentrations of albumin and normal plasma;

$$
\begin{aligned}
& \text { COP albumin }=2.8 \mathrm{c}+0.18 \mathrm{c}^{2}+0.012 \mathrm{c}^{3} \\
& \text { COP plasma }=2.1 \mathrm{c}+0.16 \mathrm{c}^{2}+0.009 \mathrm{c}^{3}
\end{aligned}
$$

(COP: mmHg, c: concentration of protein, $\mathrm{g} / 100 \mathrm{ml}$ )

Assuming that the ratio of albumin and globulins $(A / G)$ of normal plasma was 1.1 and that osmotic interactions between globulins and albumins were not significantly different from interaction between albumin and albumin, Landis and Pappenheimer calculated the following globulin equation,

$$
\text { COP globulins }=1.6 \mathrm{c}+0.15 \mathrm{c}^{2}+0.006 \mathrm{c}^{3}
$$

Our theoretical analysis focuses on these equations.

2) In 13 healthy Japanese adults, two $20 \mathrm{ml}$-samples of venous blood, one in a dried syringe and the other in one moistened with tiny amount of heparin sodium solution (500 $\mu / \mathrm{ml}$ ), were centrifuged at $3,000 \mathrm{rpm}$ for $20 \mathrm{~min}$.

After measuring the protein concentration by Lowry's method and protein composition by electrophoresis with a cellulose acetate membrane (separax), the plasma samples were stored in a cold room $\left(4^{\circ} \mathrm{C}\right)$. Within a few days the colloid osmotic pressures of these samples were measured at $25^{\circ} \mathrm{C}$ with a Hansen-Guyton osmometer, with an Amicon UM-10 membrane and a saline solution (0.15 mole/liter) as a reference (Prather et al. 1968). At the time of COP measurement the $\mathrm{pH}$ of each sample was also determined by an automatic physiologic gas analyzer.

The electrolyte concentrations of the serum samples were measured by a freezing point method.

\section{Results ANd Discussion}

Internal inconsistencies of the above mentioned three cubic equations. The first term of each equation of the three (1), (2) and (3), representing the ideal limiting law of van't Hoff, when extrapolated to zero concentration of protein, gives the average molecular weight of each protein solution as follows:

$$
\begin{aligned}
& \mathrm{COPalb} / \mathrm{c} \rightarrow \mathrm{o}=\frac{10 \mathrm{RT}}{\mathrm{Malb}}=2.8 \\
& \mathrm{COPp} 1 / \mathrm{c} \rightarrow \mathrm{o}=\frac{10 \mathrm{RT}}{\mathrm{Mpl}}=2.1
\end{aligned}
$$




$$
\mathrm{COPglb} / \mathrm{c} \rightarrow \mathrm{o}=\frac{10 \mathrm{RT}}{\mathrm{Mglb}}=1.6
$$

where R, T and M stand for the gas constant, the absolute temperature and the value of average molecular weight, resulting in $\mathrm{Malb}=69,000, \mathrm{Mpl}=92,000$ and $\mathrm{Mglb}$ $=120,000$.

In general, the average molecular weight $(\mathrm{M})$ of $\mathrm{Ni}$ solvents with molecular weights of Mi in a solution can be represented as follows:

$$
\frac{\sum \mathrm{NiMi}}{\mathrm{M}}=\Sigma \frac{\mathrm{NiMi}}{\mathrm{Mi}}
$$

and thus in plasma containing Calb and Cglb of albumin and globulins,

$$
\begin{aligned}
& \frac{\text { Calb }+ \text { Cglb }}{\text { Mpl }}=\frac{\text { Calb }}{\text { Malb }}+\frac{\text { Cglb }}{\text { Mglb }} \\
& \frac{1}{\text { Mpl }}=\frac{\text { Calb }+ \text { Cglb }}{\text { Malb }}+\frac{\text { Calb }+ \text { Cglb }}{\text { Mglb }}
\end{aligned}
$$

In the last equation, $\mathrm{Calb} / \mathrm{Calb}+\mathrm{Cglb}$ and $\mathrm{Cglb} / \mathrm{Calb}+\mathrm{Cglb}$ correspond to the fractions of albumin $(\alpha)$ and globulins $(\beta)$, respectively.

Therefore, when $\mathrm{A} / \mathrm{G}=1.1(\alpha=0.52$ and $\beta=0.48)$, substituting the previously described average molecular weights of albumin and globulins in the last equation, one can calculate Mglb as follows:

$$
\frac{1}{92,000}=\frac{0.52}{69,000}+\frac{0.48}{\mathrm{Mglb}} \quad \therefore \quad \mathrm{Mglb}=145,000
$$

Thus, the average molecular weights of plasma globulins obtained from their globulin equation does not correspond to that from van't Hoff's law. The discrepancy must be attributed to equation (3) because, as stated in the original work, the equations (1) and (2) were derived from empirical data.

The possible average molecular weight of globulins and its corresponding first term must be 145,000 and 1.3 , respectively, when the original descriptions of the first terms of the equations (1) and (2) and $A / G$ were correct (Fig. 1).

As for the second and third terms of their equations, if the osmotic interactions between albumin and globulins does not differ significantly from interaction between albumin and albumin, as also stated in the paper (Landis and Pappenheimer 1965), the relation between the three protein equations must be as follows:

$$
\mathrm{COPpl}=\alpha \cdot \mathrm{COPalb}+\beta \cdot \mathrm{COPglb} \quad(\alpha+\beta=1)
$$

Substituting the equations (1) and (2) to COPalb and COPp1, respectively, based upon $\mathrm{A} / \mathrm{G}=1.1$, the corrected globulin equation can be given by

$$
\mathrm{COPglb}=1.3 \mathrm{c}+0.14 \mathrm{c}^{2}+0.006 \mathrm{c}^{3}
$$




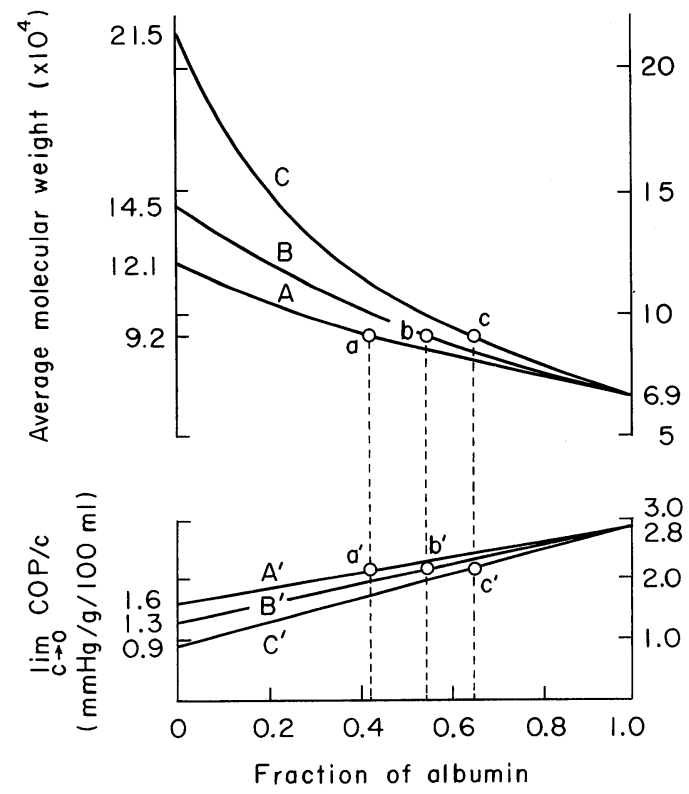

Fig. 1. The three curves (top) and straight lines (bottom) represent the possible average molecular weights of plasma in relation to its protein composition and the corresponding first term of the plasma COP equations, respectively. $A\left(A^{\prime}\right), B\left(B^{\prime}\right)$ and $C\left(C^{\prime}\right)$ correspond to the first terms of equations (1) and (2), (10) and (14), respectively. Because equations (1) and (2) had empirical support and the resultant estimate of $\mathrm{A} / \mathrm{G}$ ratio of normal plasma was 1.1 (albumin fraction 0.52), B and $\mathrm{B}^{\prime}$ must be correct, but not A and A'. Substituting the current estimate of albumin fraction of normal plasma (0.64) for (1) and (2), one may obtain the current estimate of plasma globulins: 215,000 and eventually 0.9 as the first term of the globulin equation.

Correction of globulin equation for improved protein analysis. The recent technical improvement in protein analysis revealed that the average albumin fraction of normal plasma is much higher than the estimate made in the original reports of Landis and Pappenheimer.

Recently, electrophoretic analysis with cellulose acetate is in world-wide use in the clinical and biological fields because of its excellent reproducibility and handy procedure. Analysing plasma of 46 healthy Japanese adults with the procedure, Nishi (1968) reported the average value of normal plasma to be $0.642+$ 0.025. Our data on the average albumin fraction of normal plasma based upon 13 healthy Japanese volunteers as shown in table 1 was much closer to theirs than that of the original estimate of 0.52 .

Substituting equations (1), (2) and 0.642 to the COPalb, COPpl and $\alpha$ of equation (10), respectively, the authors mathematically subtracted a new globulin equation as follow:

$$
\begin{aligned}
& (2)=0.642 \times(1)+0.358 \times \mathrm{COPglb} \\
& \therefore \quad \text { COPglb }=0.9 \mathrm{c}+0.12 \mathrm{c}^{2}+0.004 \mathrm{c}^{3}
\end{aligned}
$$


The original equations cannot be generalized at all, whereas one may calculate the colloid osmotic pressure of plasma with any composition of albumin and globulins from the following equation:

$$
\mathrm{COPpl}=\alpha(1)+\beta(12)
$$

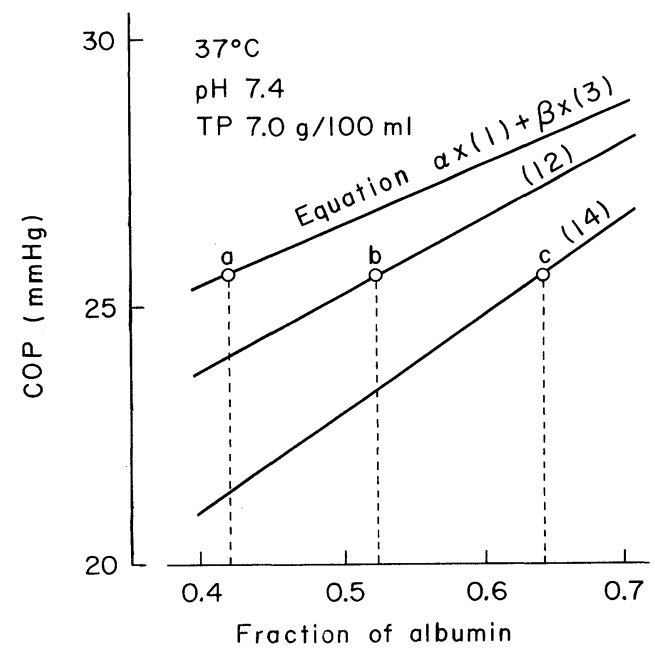

Fig. 2. The three straight lines represent the relationships between $\mathrm{COP}$ and protein compositions of the possible three plasma equations. As described in the text, equations $\alpha \times(1)+\beta \times(3)$ and (12) cannot be used to estimate the current plasma COP from plasma proteins, because of the inadequate values of the protein composition. Only $\mathrm{c}$ on the equation (14) satisfies the current estimate of the protein composition of normal human plasma.

TABLE 1. Comparison of plasma colloid osmotic pressures between the values directly measured at $25^{\circ} \mathrm{C}$ with a hand-made oncometer (COPm) and calculated from equation (14) based upon plasma protein concentration and composition (COPc).

\begin{tabular}{|c|c|c|c|c|c|c|c|c|c|c|}
\hline Age & Sex & $\begin{array}{c}\text { Hematocrit } \\
(\%)\end{array}$ & $\begin{array}{l}\text { Electrolyte } \\
\text { (mOs) }\end{array}$ & $\mathrm{pH}$ & $\begin{array}{c}\text { T.P. } \\
(\mathrm{g} / 100 \mathrm{ml})\end{array}$ & $\begin{array}{l}\text { Albumin } \\
(\%)\end{array}$ & $\mathrm{A} / \mathrm{G}$ & $\begin{array}{l}\mathrm{COPm} \\
\mathrm{cmH}_{2} \mathrm{O}\end{array}$ & $\begin{array}{c}\mathrm{COPc} \\
\mathrm{cmH}_{2} \mathrm{O}\end{array}$ & $\begin{array}{l}\mathrm{COPm} / \\
\mathrm{COPc}\end{array}$ \\
\hline 40 & $\mathrm{M}$ & 54 & 310 & 7.59 & 7.9 & 66.9 & 2.02 & 37.5 & 37.0 & 1.01 \\
\hline 39 & M & 46 & 295 & 7. 47 & 7.2 & 60.1 & 1.51 & 35.5 & 35.0 & 1.01 \\
\hline 38 & M & 45 & 300 & 7.49 & 7.5 & 64.6 & 1. 82 & 40.5 & 38.5 & 1.05 \\
\hline 27 & M & 50 & 301 & 7. 61 & 7.7 & 61.1 & 1. 75 & 40.5 & 39.0 & 1.04 \\
\hline 26 & M & 46 & 297 & 7.51 & 8.0 & 62.9 & 1. 69 & 42.5 & 42.2 & 1.01 \\
\hline 25 & $\mathrm{M}$ & 44 & 291 & 7.51 & 7.1 & 66.2 & 1.96 & 37.5 & 36.0 & 1.04 \\
\hline 47 & $\mathrm{~F}$ & 41 & 306 & 7.52 & 7.3 & 60.7 & 1. 54 & 35.0 & 36.0 & .97 \\
\hline 29 & $\mathbf{F}$ & 40 & 299 & 7.50 & 7.4 & 61.4 & 1. 59 & 40.0 & 37.2 & 1.08 \\
\hline 25 & $\mathrm{~F}$ & 38 & 295 & 7. 52 & 7.8 & 58.7 & 1. 42 & 38.2 & 39.0 & .99 \\
\hline 24 & $\mathbf{F}$ & 37 & 300 & 7. 53 & 7.9 & 62.2 & 1. 64 & 38.0 & 41.0 & .93 \\
\hline 23 & $\mathbf{F}$ & 37 & 294 & 7. 50 & 7.1 & 57.2 & 1.34 & 33.0 & 33.5 & .99 \\
\hline 20 & $\mathbf{F}$ & 44 & 308 & 7. 44 & 7.9 & 61.7 & 1. 61 & 40.0 & 41.0 & .98 \\
\hline 20 & $\mathbf{F}$ & 38 & 305 & 7.47 & 7.7 & 65.7 & 1.91 & 40.0 & 40.2 & 1.00 \\
\hline \multirow{2}{*}{\multicolumn{2}{|c|}{$\begin{array}{l}29.5 \\
\pm 8.6\end{array}$}} & 43 & 300 & 7.52 & 7.6 & 62.3 & 1. 68 & 38.3 & 38.9 & 1. 01 \\
\hline & & \pm 5 & \pm 6 & \pm .05 & \pm 0.3 & \pm 2.9 & \pm .21 & \pm 2.7 & \pm 2.6 & \pm .04 \\
\hline
\end{tabular}




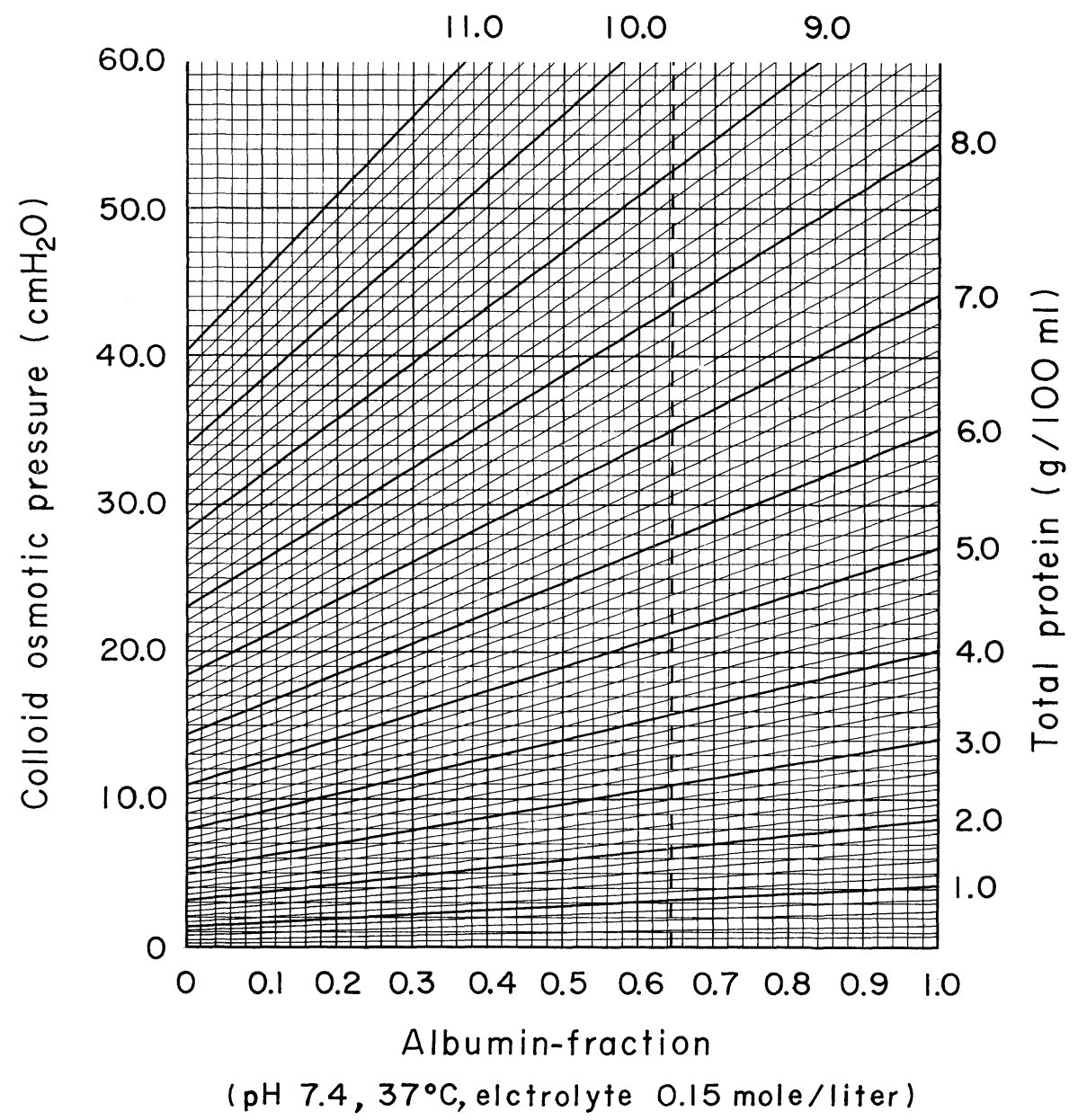

Fig. 3. The nomogram was developed from the equation $\mathrm{COPpl}=\alpha\left(2.8 \mathrm{c}+0.18 \mathrm{c}^{2}+0.012 \mathrm{c}^{2}\right)$ $+\beta\left(0.9 \mathrm{c}+0.12 \mathrm{c}^{2}+0.004 \mathrm{c}^{3}\right)$, where $\alpha, \beta$ and $\mathrm{c}$ stand for albumin and globulin fractions, and protein concentration of plasma, assuming that Landis and Pappenheimers' albumin- and plasma-equations are correct and that the current estimate of albumin fraction of the normal human plasma is 0.642 .

where $\alpha$ and $\beta$ stand for albumin and globulin fractions, respectively.

$$
\mathrm{COPpl}=\alpha\left(2.8 \mathrm{c}+0.18 \mathrm{c}^{2}+0.012 \mathrm{c}^{3}\right)+\beta\left(0.9 \mathrm{c}+0.12 \mathrm{c}^{2}+0.004 \mathrm{c}^{3}\right)
$$

where $\mathrm{c}$ stands for protein concentration in $\mathrm{g} / 100 \mathrm{ml}$ and $\mathrm{COPpl}$ for plasma protein colloid osmotic pressure in $\mathrm{mmHg}$ at $\mathrm{pH} .7 .4,37^{\circ} \mathrm{C}$ and electrolyte concentration of $0.15 \mathrm{~mole} / \mathrm{liter}$. For practical convienience, the authors developed the last equation on a nomogram (Fig. 3).

Relationship between the COP values of direct measurement and of our equation. As shown in Table 1, the directly measured colloid osmotic pressure of normal 
plasma, $38.3 \pm 2.7 \mathrm{cmH}_{2} \mathrm{O}$, was close to the data calculated from our equation (14), $38.9 \pm 2.6 \mathrm{cmH}_{2} \mathrm{O}$, and the ratio of the two was $1.01 \pm 0.04$.

The major factors affecting the values of the directly measured plasma COP were the temperature and $\mathrm{pH}$. From the ideal limiting van't Hoff's law, the relation between the first terms at $37^{\circ} \mathrm{C}$ of the body temperature and $25^{\circ} \mathrm{C}$ of the measured temperature must be $310: 298$. Assuming that the second and the third terms of the plasma equation also maintain the same relationship, the COP at $25^{\circ} \mathrm{C}$ must be corrected by $+4 \%(310 / 298=1.040)$, resulting in its average value of 39.1 $\mathrm{cmH}_{2} \mathrm{O}$.

On the other hand, $\mathrm{pH}$ of plasma also affects COP. Our preliminary data on the $\mathrm{pH}$ correction factor at $25^{\circ} \mathrm{C}$ is $\mathrm{COP}(\mathrm{pH} 7.4)=\mathrm{COP}(\mathrm{pH} \mathrm{x})=0.05 \mathrm{c}^{2}(7.4-\mathrm{pHx})$, where $\mathrm{x}$ and $\mathrm{c}$ stand for the $\mathrm{pH}$ at which $\mathrm{COP}$ is measured and the protein concentration of plasma, respectively. The average value of $\mathrm{pH}$ of our plasma is 7.52 and the correction factor for $\mathrm{pH}$ results again in the average value of $\mathrm{COP} 39.5 \mathrm{~cm}$ $\mathrm{H}_{2} \mathrm{O} \quad\left[=38.3 \mathrm{cmH}_{2} \mathrm{O} \times 1.040+0.05 \times 7.6^{2}(7.4-7.5)\right]$.

\section{Acknowledgments}

We are deeply indebted to Mr. K. Suzuki for his variable contribution to measuring plasma colloid osmotic pressure and also to Miss M. Akahira for her assistance to complete this manuscript.

\section{References}

1) Demling, R.H., Manohar, M. \& Will, J.A. (1980) Relationship between the measured and calculated colloid osmotic pressure of plasma and lung lymph in the sheep. Lymphology, 13, 18-23.

2) Landegard-Pederson, H.J. (1967) Measurement of colloid osmotic pressure in patients. Scad. J. clin. Lab. Invest., 20, 79-87.

3) Landis, E.M. \& Pappenheimer, J.R. (1965) Exchange of substances through the capillary walls. In: Handbook of Physiology, Sec. Circulation, Chap. 29, American Physiological Society, Washington D.C., pp. 961-1034.

4) Navar, P.D. \& Navar, L.G. (1977) Relationship between colloid osmotic pressure and plasma protein concentration in the dog. Amer. J. Physiol., 233, 295-298.

5) Nishi, S. (1968) Electrophoretic analysis of plasma proteins of healthy adult Japanese. Jap. J. Biophysics, 13, 299-304.

6) Nitta, S., Yamane, Y., Ohnuki, T., Chigira, H., Ohtuka, T., Nakada T. \& Staub, N.C. (1976) Adequacy of applying calculated colloid osmotic pressure to transcapillary fluid exchange. Proc. Xth Int. Cong. Ang., Tokyo, Japan, p. 129.

7) Prather, J.W., Gaar, K.A., Jr. \& Guyton, A.C. (1968) Direct continuous recording of plasma colloid osmotic pressure of whole blood. J. appl. Physiol., 24, 602-605.

8) Zweifach, B.W.\& Interglieta, M. (1971) Measurement of blood colloid osmotic pressure, Comparative study of different species. Microvasc. Res., 3, 83-93. 